\title{
PLANEJAMENTO E CONTROLE DA PRODUÇÃO EM DUAS EMPRESAS DO SETOR GRÁFICO EM UM MUNICÍPIO DO ESTADO DO AMAZONAS
}

\section{ARTIGO ORIGINAL}

SERRÃO, Victor Antunes de Souza ${ }^{1}$

ARAÚJO, Jucymara Soares ${ }^{2}$

JUSTI, Jadson ${ }^{3}$

SERRÃO, Victor Antunes de Souza. ARAÚJO, Jucymara Soares. JUSTI, Jadson. Planejamento e controle da produção em duas empresas do setor gráfico em um município do estado do Amazonas. Revista Científica Multidisciplinar Núcleo do Conhecimento. Ano 04, Ed. 08, Vol. 06, pp. 101-111. Agosto de 2019. ISSN: 24480959

\section{RESUMO}

No município de Parintins, as indústrias gráficas e de cortinas são formadas por micro, pequenas e médias empresas, nas quais frequentemente se observam dificuldades às inovações tecnológicas e ao desenvolvimento do setor. Os produtos destas empresas, tais como camisas, bandeiras, persianas e almofadas, possuem grande qualidade, mas que muitas vezes são prejudicados devido às falhas no processo de produção. Para que a produção seja eficiente, é importante haver interação e

1 Especialista em Gestão Pública pela Universidade do Estado do Amazonas. Graduando em Administração pela Universidade Federal do Amazonas.

${ }^{2}$ Graduanda em Administração pela Universidade do Estado do Amazonas.

3 Professor da Universidade Federal do Amazonas; Mestrado em Psicologia; Especialização em Bioética; Graduação em Pedagogia; Graduação em Fonoaudiologia. 
disponibilidade entre os recursos na quantidade e no momento necessário. Nesse sentido, o objetivo deste trabalho é descrever como as indústrias gráficas e de persianas, no município de Parintins, utilizam as práticas do planejamento e controle da produção em seus processos produtivos e o impacto de tais práticas nos modelos de negócios das referidas empresas. Com isso, acredita-se que essa atividade se mostre relevante para novos tempos uma vez que se relaciona diretamente com as atividades primárias do município de Parintins, gerando impactos diretos na economia da cidade, que, basicamente, tem sua economia subsidiada pelas atividades de comércio e artesanato, o que destaca a relevância dessa atividade no município. Metodologicamente, tem-se um estudo de caso descritivo com abordagem qualitativo cujos dados foram coletados por meio de observação in loco, entrevista semiestruturada com os proprietários e análise da transcrição dos dados obtidos, em duas empresas gráficas e de cortinas da cidade de Parintins/am. Com base nos resultados encontrados, percebe-se que as empresas, por estarem em uma região com pouco desenvolvimento tecnológico, possuem sistemas de produção primários que acarretam em perda de matérias primas, processos produtivos e principalmente, dinheiro, devido à ausência de sistemas que gerenciem, em tempo real, as variações de demanda, estoque, pedidos processados e número de pedidos vendidos. Faz-se necessário a utilização de ferramentas tecnológicas, mudanças na cultura organizacional e foco maior na tendência e nas exigências dos clientes, pautas muitas vezes ignorados pelos empresários de Parintins.

Palavras-Chaves: Indústria Gráfica, Indústria de Cortinas, Gestão da Produção.

\section{INTRODUÇÃO}

O objetivo do Planejamento e Controle da Produção (PCP) é gerenciar a produção de uma empresa para que esta atinja os seus objetivos com a maior eficiência possível, agregando valor à linha de produção. Para que a produção seja eficiente, é importante que haja interação e disponibilidade entre os recursos na quantidade e no momento necessário. Essa integração envolve decisões que, para serem tomadas de maneira coerente, exigem conhecimento a respeito do assunto. 
Partindo dessa perspectiva, o estudo em relação ao PCP mostra que as empresas gráficas e de cortinas em Parintins necessitam de melhorias significativas, pelo fato das empresas, ainda utilizarem tecnologias manuais, sem o viés tecnológico adequado, que contribuem para a perda de competitividade. Isso ocasiona problemas com a produção, estoque, tempo de processamento dos pedidos e entrega dos pedidos ao cliente.

Nesse sentido, o objetivo deste trabalho é descrever como as indústrias gráficas e de persianas, no município de Parintins, utilizam as práticas do planejamento e controle da produção em seus processos produtivos e o impacto de tais práticas nos modelos de negócios das referidas empresas. Com isso, acredita-se que essa atividade se mostre relevante para novos tempos uma vez que se relaciona diretamente com as atividades primárias do município de Parintins, gerando impactos diretos na economia da cidade, que, basicamente, tem sua economia subsidiada pelas atividades de comércio e artesanato, o que destaca a relevância dessa atividade no município.

Metodologicamente, trata-se de um estudo de caso descritivo com abordagem qualitativa cujos dados foram coletados por meio de entrevistas semiestruturadas com os proprietários, observação in loco e transcrição dos dados obtido, em duas empresas lócus deste estudo. O critério de inclusão adotado para a escolha dessas empresas fora que os estabelecimentos trabalhassem com atividades de produção gráfica e cortinas e que seus proprietários aceitassem voluntariamente, dentro do horário de expediente, a participar do estudo em questão. Para a garantia do respaldo ético dessa pesquisa, optou-se pelo anonimato das empresas pesquisadas por meio da assinatura do Termo de Consentimento Livre e Esclarecido (antes mesmo de qualquer procedimento por parte dos pesquisadores) para que se fosse permitida a coleta de dados nas empresas. As empresas pesquisadas, serão identificadas, ao longo do trabalho, pelas nomenclaturas Empresa Gráfica e Indústria de Cortinas. 


\section{CONSIDERAÇÕES SOBRE O SETOR GRÁFICO E DE CORTINAS}

O Setor Gráfico é um dos setores em expansão no Brasil. Existem hoje, aproximadamente 20,3 mil empresas registradas no território nacional. A receita bruta destas indústrias supera $R \$ 23$ bilhões anuais e são responsáveis responsável por 315 mil empregos, de forma direta e indireta, segundo o estudo da ABIGRAF (Associação Brasileira da Indústria Gráfica).

Ribeiro et al. (2004) apresenta um modelo de PCP para uma indústria gráfica. Em uma gráfica convencional, a rotina de trabalho está intimamente ligada à flexibilidade que esta tem de atender as exigências dos clientes. Isso significa dizer que a gráfica deve adaptar a sua produção às funções do produto solicitado pelo cliente. $\mathrm{Na}$ indústria gráfica, os serviços de impressão sob demanda possuem como principal característica os pequenos prazos de entrega. Gráficas geralmente trabalham com encomendas e além disso, geralmente ocorre baixa tiragem de produção, grande variabilidade de títulos e grande volatilidade de conteúdo.

A Fábrica De Cortinas se enquadra no setor têxtil, um dos setores mais lucrativos do Brasil. Segundo a ABIT (Associação Brasileira da Indústria Têxtil), em 2018, esta área movimentou mais de US $\$ 50$ bilhões, empregando mais de 1,65 milhão de pessoas, 75\% composto por mão-de-obra feminina (GONÇALVES, 2019). Atualmente, o Brasil possui mais de 30 mil empresas que trabalham com a produção de cortina em suas diversas dimensões (GONÇALVES, 2019).

Sobre o nicho de mercado de produção de cortinas, tem-se as seguintes considerações:

Quanto ao mercado específico de cortinas, não há dados publicados sobre o crescimento do setor. Pode-se afirmar que o segmento é pontuado por concorrentes informais e costureiras caseiras que prestam serviços no mercado informal. O empresário de confecção de cortinas deve saber que irá concorrer diretamente com as costureiras artesanais e indiretamente com os fabricantes de persianas e sua extensa rede de

RC: 35968

Disponível em: https://www.nucleodoconhecimento.com.br/administracao/controle-da-producao 
distribuidores autorizados. Devido ao risco intrínseco ao negócio, recomenda-se a realização de ações de pesquisa de mercado para avaliar a demanda e a concorrência (SEBRAE, 1990, p.6).

Portanto, entende-se que o mercado de cortinas possui vasta potencialidade de crescimento, no entanto, deve-se tomar cuidados com as atividades essenciais para a sobrevivência nesse segmento, como a necessidade de conhecer as tendências e a concorrência.

\section{RESULTADOS E DISCUSSÃO}

\subsection{A EMPRESA GRÁFICA}

Inaugurada no dia 23 de setembro de 2014, atuando há 4 anos no mercado, a Empresa Gráfica é uma das gráficas da cidade de Parintins. Atualmente, a empresa opera com aproximadamente 13 funcionários estruturados em gerente, recepcionista e colaboradores de produção, na parte de costura e design, sendo 11 pessoas na área de produção e 2 pessoas na área administrativa. Hierarquicamente, a empresa de divide conforme esquema a seguir:

Esquema 1: Hierarquia empresarial da empresa gráfica.

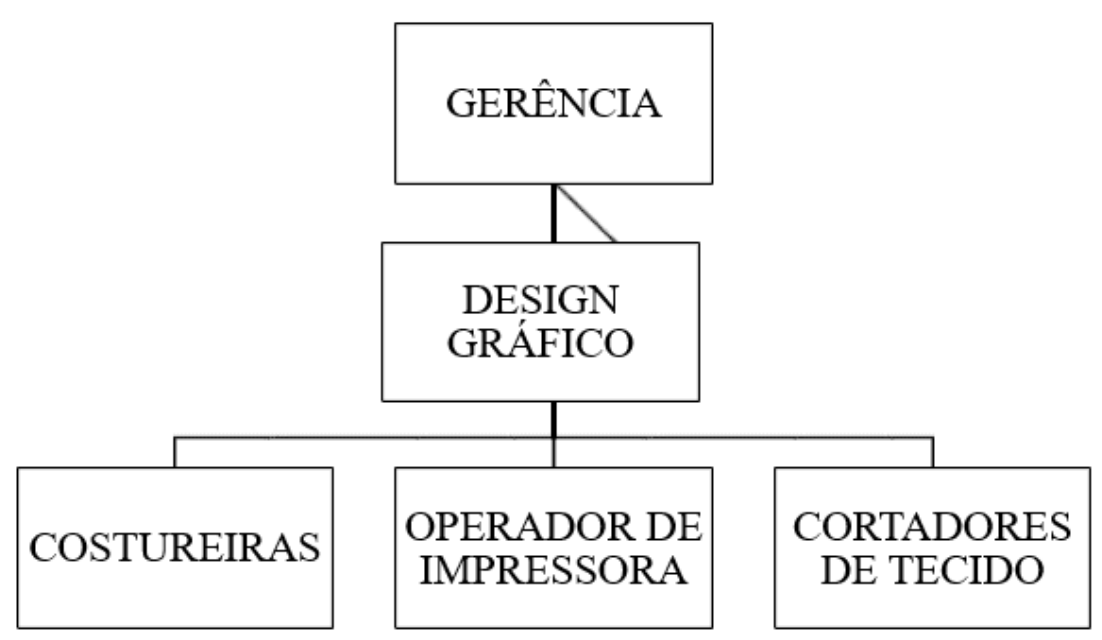

Fonte: Os autores, 2019. 
A empresa fabrica diversos produtos com características distintas, como fardamentos empresariais e escolares, equipamentos esportivos, abadás, bandeiras, almofadas, banners, dentre outros. Para a produção, utiliza-se o computador para fazer a arte gráfica e também o processo de impressão; há uma impressora de grande porte onde é feita a impressão das camisas no papel; uma máquina de corte, responsável pelo corte de tecidos em grandes quantidades; a prensa térmica, onde transfere-se a tinta do papel para o tecido; as máquinas de costura e a parte do acabamento. O maquinário é todo da empresa, assim como o ponto.

Verificou-se que não existe uma linha de produção pré-definida, sendo o processo produtivo ajustado de acordo com o produto a ser feito. Na realidade, a gráfica programa sua produção de acordo com a demanda. Alguns trabalhos são frequentes, como a fabricação de artigos esportivos e fardamentos escolares. Por esta razão, a produção é feita sob encomenda e não se utiliza a produção em série. Desta maneira, o planejamento e o controle da produção têm como principal objetivo garantir a continuidade da produção, evitando a falta de matéria-prima visando atender aos prazos de entrega. Para atingir tal objetivo, a área de PCP procura estudar a demanda e ter uma relação próxima com as áreas de venda, pois não existe uma uniformidade da demanda, sendo está prevista de acordo com a necessidade do mercado.

Por outro lado, observa-se certa sazonalidade nesta demanda, que é considerada no planejamento da produção. Verifica-se um aumento significativo da demanda nos meses de maio até junho, época da festa do boi-bumbá. Pode-se também destacar o período dos jogos escolares e o do carnaval. Nesses meses, a gráfica funciona acima da sua capacidade normal de produção, a fim de atender toda a demanda.

Em relação à matéria-prima, há um planejamento para a arrecadação de capital e a compra do material da produção é separada. Na época do boi-bumbá, esse planejamento é feito baseado no ano anterior e todo o controle é feito por cada setor. Para a matéria-prima chegar até Parintins, utiliza-se o transporte via fluvial. As matérias-primas geralmente vêm de Manaus. A empresa trabalha para reduzir os custos de transporte, optando por terceiriza-lo. De acordo com Shingo (1997), uma 
das prioridades no esforço de redução de custos é a eliminação ou redução do transporte, pois, em geral, o transporte ocupa em média $45 \%$ do tempo total de fabricação de um item. Tais efeitos ocasionam muitas dificuldades para o escoamento eficiente de mercadorias.

A dificuldade de se conseguir matérias primas, por exemplo é a ausência de materiais em Manaus, capital do estado e metrópole mais próxima de Parintins. A tinta, por exemplo, tem que vir de São Paulo e, para chegar em Parintins, são 40 dias pela transportadora. Assim, a matéria-prima torna-se um dos principais problemas na gestão de produção da empresa, o que ocasiona dificuldades na hora da entrega e diversas "perdas por espera". O desperdício de espera origina-se de um intervalo de tempo no qual nenhum processamento, transporte ou inspeção é executado (GHINATO, 1996). Esse tipo de perda ocorre principalmente pela falta de balanceamento do processo de produção que ocasiona a paralisação de postos de trabalho e resulta numa baixa taxa de ocupação de equipamentos (KLIPPEL, 2008).

Como principais dificuldades e desafios da área estão o cumprimento dos prazos de entrega e o lead time de entrega. Para minimizar os atrasos, são estabelecidas prioridades a partir de critérios como forma de pagamento, melhor performance financeira e fidelidade do cliente. Vale lembrar que a gráfica precisa ser rápida em suas operações devido à alta exigência dos clientes. Este problema traz a necessidade de uma busca contínua pela redução do tempo de processo. A busca pela melhoria atualmente é um princípio de sobrevivência, sendo que as empresas que não o adotarem tendem a desaparecer, mais cedo ou mais tarde (MARTIN, 1996). 
Figura 1. Produtos da empresa gráfica

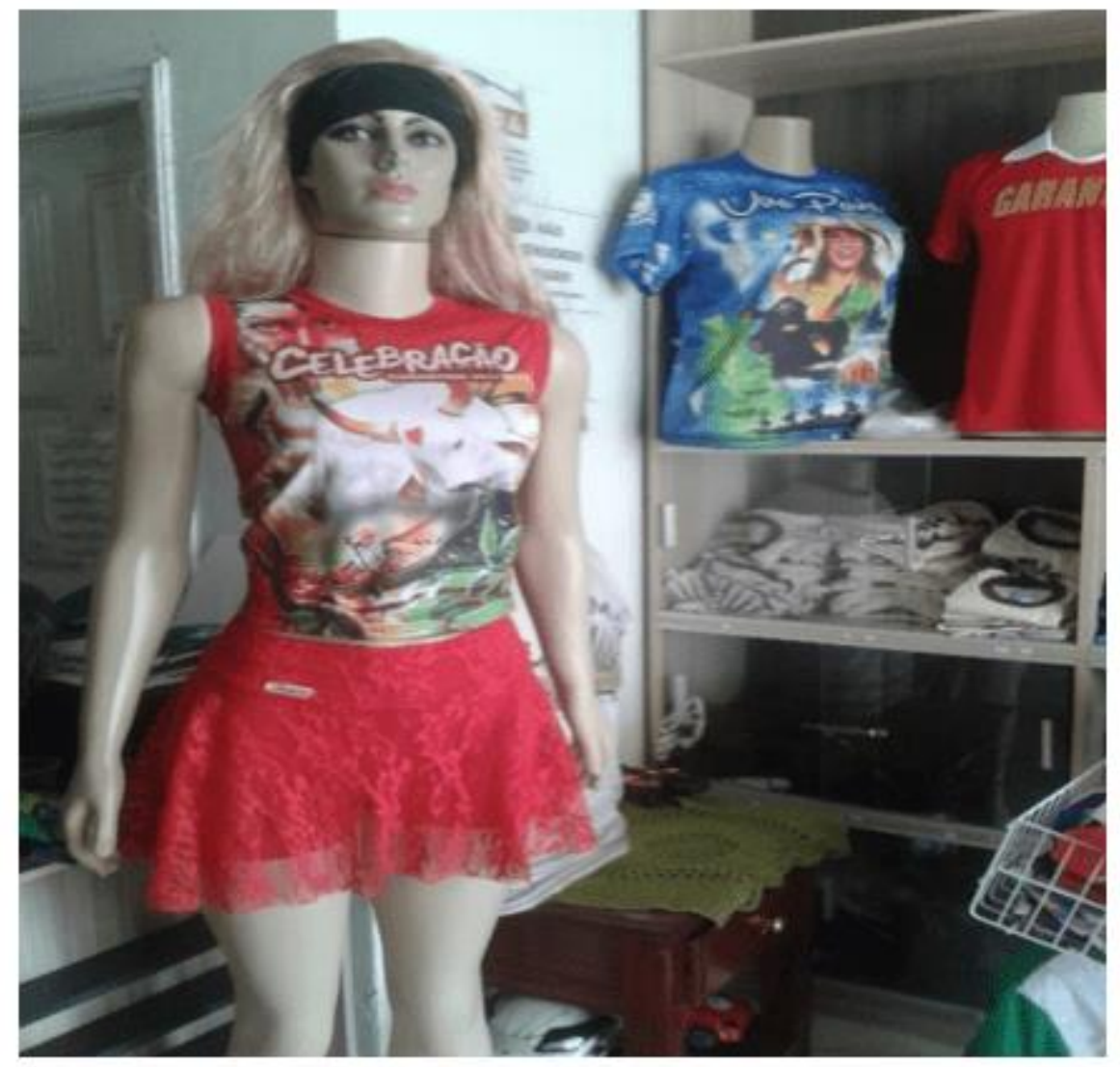

Fonte: Os autores, 2019. 
Figura 2. PCP da empresa gráfica

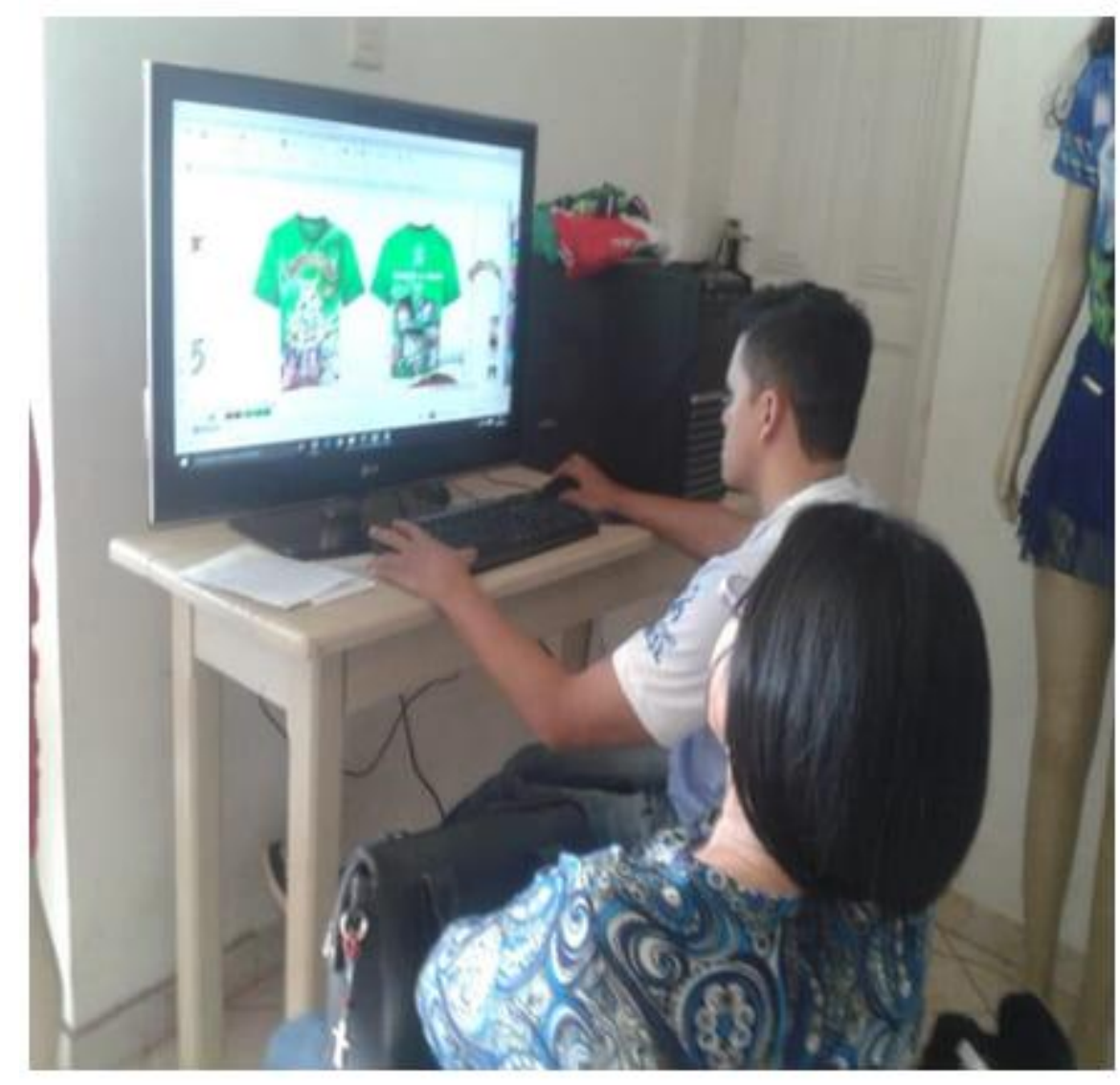

Fonte: Os autores, 2019.

No processo de fabricação, é passado uma lista para cada setor: impressão, prensagem, corte e costura. Quando a matéria-prima está no setor de prensagem é tudo corrigido, e caso haja algum erro não identificável, ele é identificado no setor de costura. Os materiais utilizados na produção são tintas sublimáticas (tintas especiais, papel, pano e outros matérias para o acabamento). A manutenção das máquinas é feita de forma corretiva. Quando há algum problema, precisa-se solicitar técnicos de Manaus, mas apenas em casos de emergência. Para se operar essas maquinas, temse um treinamento básico, pois configurar e operar os sistemas é algo simples.

Com relação aos estoques, cada produto e material fica no seu ambiente. O papel é sempre armazenado no mesmo local da máquina e não existe um local próprio para o estoque desses materiais, o que pode ocasionar desorganização no processo 
produtivo e custos mais elevados com estoques. De acordo com Shingo (1996) uma grande dificuldade para se atacar as perdas por estoque é a concepção ocidental de que o estoque é um "mal necessário", pois funciona como uma segurança para a oscilação da demanda e confiabilidade das máquinas e operações. $O$ valor dos produtos da gráfica não é um valor exato: Há um valor em média de $R \$ 20,00$ a $R \$$ 25,00 reais na produção de camisas. O que define o valor final do produto é o modelo, quantidade e cor.

\subsection{A INDÚSTRIA DE CORTINAS}

Fundada em 2006 e atuando há 12 anos no mercado de fabricação de cortinas e persianas, a Industria de Cortinas opera como a única empresa do ramo no município de Parintins. Atualmente, a empresa possui um quadro de funcionários informais, com apenas 4 pessoas, sendo o gerente o grande responsável por executar todas as funções da empresa, conforme esquema a seguir:

Esquema 2: Hierarquia empresarial da indústria de cortinas.

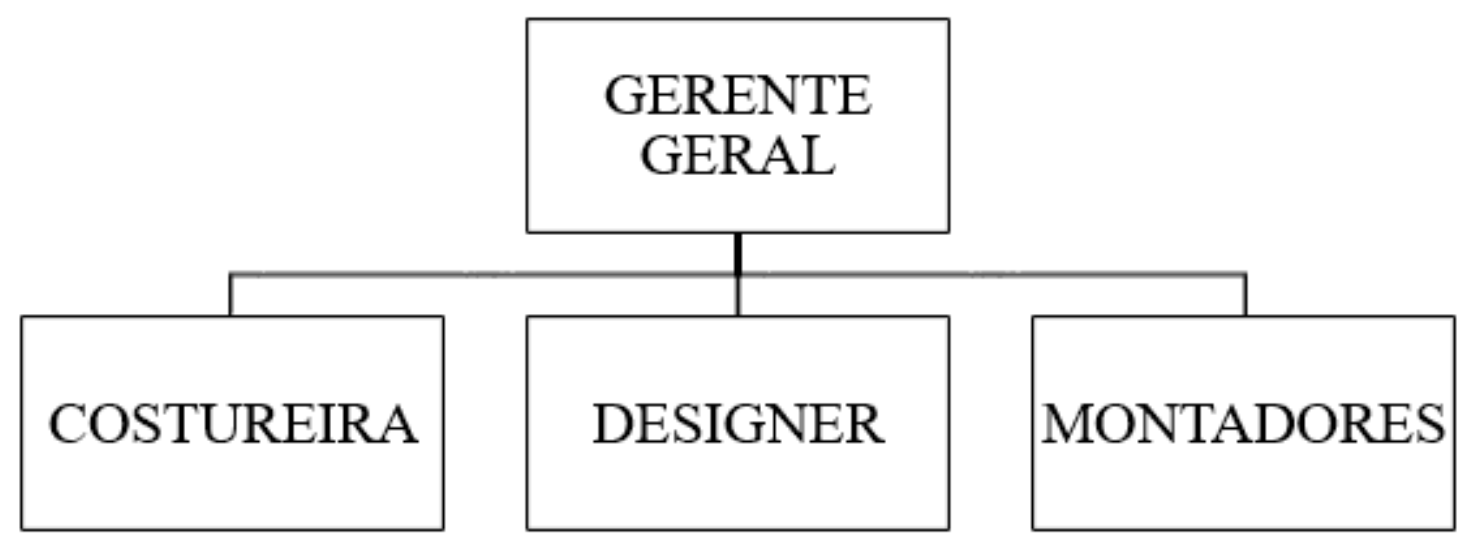

Fonte: Os autores, 2019.

Com relação à estrutura da produção, a empresa não tem estoque. Como a maioria dos materiais tem até 6 metros, o que requer muito espaço, não há espaço para estoques. Pede-se o tanto que se vende. O gerente tem o controle do fluxo de 
materiais que entram e saem, tendo em mente o cálculo de todo o fluxo e de cada peça que irá compor cada persiana.

A empresa só trabalha com pedidos. Assim que são recebidos os pedidos, as informações são digitadas no banco de dados da empresa para verificar se os materiais necessários às manufaturas das persianas encontram-se disponíveis, confirmando preços, condição de pagamento e prazos de entrega estabelecidos pelo cliente. A indústria de cortinas trabalha com o que é definido como customização de massa, que segundo Kotler (1999, p. 228), "é a habilidade de preparar uma base consistente de produtos e comunicações para atender as exigências de cada consumidor, fazendo produtos sob medida, com grande variedade de opções de cores e padrões, além de um prazo de entrega curto, oscilando entre um e três dias." Dependendo da situação, a entrega pode ser garantida no mesmo dia do pedido.

Para a fabricação destes produtos, exige-se uma grande flexibilidade da produção. As persianas têm seu processo produtivo dividido em duas partes principais: a montagem dos trilhos e a confecção das lâminas. Na montagem dos trilhos há variação de tamanho e cinco modelos de abertura. Já as persianas podem ser de PVC, ou de tecido. A empresa oferece mais de 500 (quinhentas) combinações de cores, padrões e acabamentos, sem contar largura e comprimento, uma vez que as encomendas são sob medida, utilizando da própria estratégia de manufatura. A indústria de cortinas produz persianas, cortinas, carpetes para palcos e alguns meios de transportes, como lanchas. Para as lanchas, pega-se os carpetes de borracha e faz-se o molde da lancha, envolvendo os processos de cortes, recortagens e colagem para que se faça o assoalho. Já para os carpetes em palco, presta-se esse serviço em festas. 
Figura 3. Setor de gerência e produção da empresa

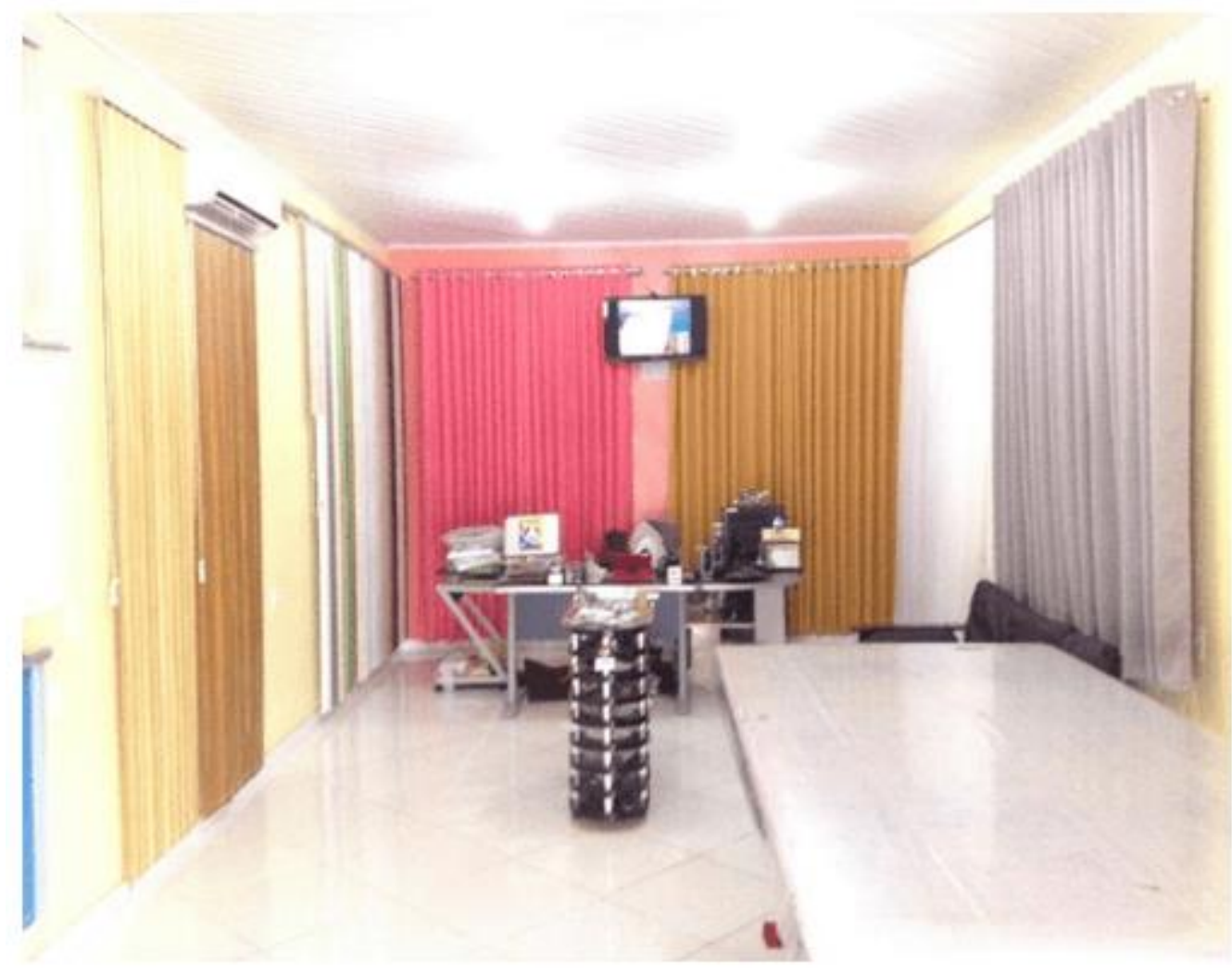

Fonte: Indústria de Cortinas, 2019. 
Figura 4. Modelo de cortinas da empresa

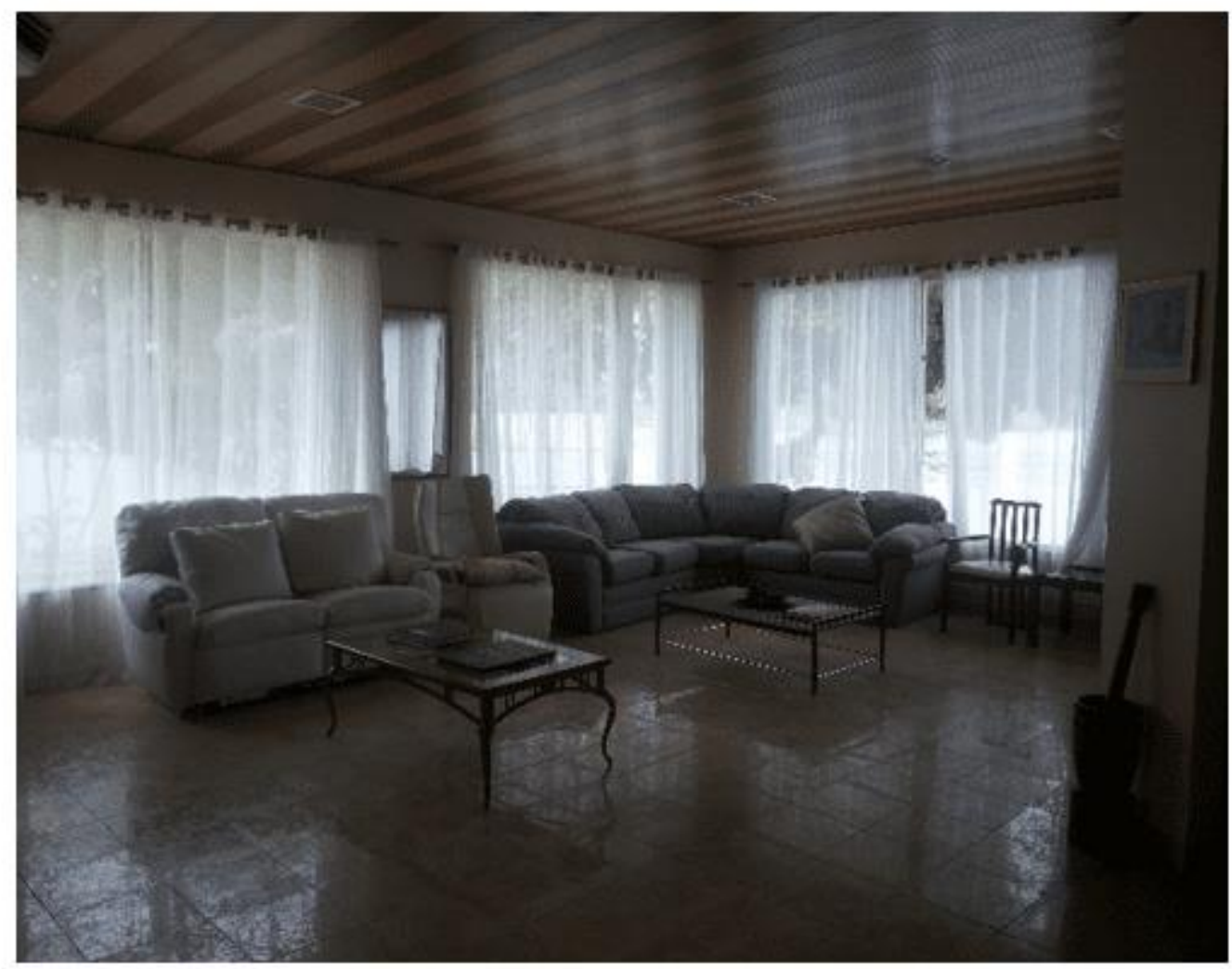

Fonte: Indústria de Cortinas, 2019.

No que tange a entrega dos materiais, utiliza-se o transporte fluvial e aéreo, onde todos os pedidos são calculados, cada peça que será necessária para a produção das cortinas. Os pedidos são feitos até três vezes na semana, mas com a queda na demanda, são realizados por quinzenas. A utilização do meio de transporte aéreo é apenas em caso de emergência, quando o cliente está necessitando de imediato da cortina. Todas as compras são feitas à vista e com o dinheiro do frete embutido.

Observou-se que a empresa não trabalha com normas técnicas para atuar nesse ramo. Não se utilizam EPI's pois as maquinas de fabricação das persianas são de pequeno porte e não os prejudica. Também não há nenhum órgão fiscalizador que regulamente as atividades da empresa. O valor da persiana tem um valor fixo por $\mathrm{m}^{2}$ onde têm-se de $R \$ 115,00$ e $R \$ 135,00$. Já a cortina depende muito do pano que será usado e do modelo. O valor de produto vária, pois têm-se de $\mathrm{R} \$ 2000,00 \mathrm{R} \$ 1000,00$ 
$R \$ 500,00$, portanto não há um valor fixo, pois, o preço oscila conforme o tamanho e o modelo, ou seja, quanto mais acessórios, mais cara a cortina fica.

\section{CONSIDERAÇÕES FINAIS}

Este artigo trouxe um estudo a respeito de uma literatura pouco abordada em cidades com baixa aglomeração de pessoas e baixa renda. A temática adotada nesse artigo é de fato pouco debatida no meio científico, a qual se é mais comum verificar estudos, dessa natureza, em grandes cidades ou em grandes complexos empresariais. Tal consideração demonstra a relevância deste estudo para a condução de novas pesquisas que possam explorar as nuances do tema diante das influências do PCP com as empresas gráficas e de cortinas.

Dessa maneira, o artigo cumpriu com seu objetivo ao descrever como as empresas lócus deste estudo utilizam dos modelos do PCP em seus processos produtivos e como isso afeta seus modelos de negócios. Percebe-se, por meio das reflexões descritivas apresentado ao longo deste manuscrito, que o PCP nas referidas empresas, em Parintins, apresenta aplicações manuais sem o viés tecnológico adequado, que contribuem principalmente para a perda de competitividade. Isso ocasiona problemas com a produção, estoque, tempo de processamento dos pedidos e entrega dos pedidos ao cliente. As consequências são preocupantes uma vez que as empresas possuem grandes empecilho de crescerem na atividade e ofertarem números maiores de empregos, diante de uma cidade com taxa de desemprego acentuada.

Diante dos resultados obtidos, os proponentes desta pesquisa acreditam que se faz necessária uma adaptação própria para o avanço na condução evolutiva dos negócios aqui abordados. Faz-se necessário utilização de ferramentas tecnológicas, mudanças na cultura organizacional e foco maior na tendência e nas exigências dos clientes, pautas muitas vezes ignorados pelos empresários de Parintins. O desafio é ser capaz de fazer transposição de técnicas e ferramentas administrativas do PCP, 
apresentadas ao longo deste trabalho, adaptando o raciocínio ao modelo de negócio e inferindo formas eficientes e modernas para melhorar a gestão produtiva.

\section{REFERÊNCIAS}

Associação Brasileira da Indústria Gráfica. Importância da Indústria Gráfica, 2016. Disponível em: http://www.abigraf.org.br/. Acesso: maio/2018;

GHINATO, Paulo. Sistema Toyota de Produção: mais do que simplesmente just-intime. Caxias do Sul: EDUSC, 1996.

GONÇALVES, V. Como montar uma empresa de confecção de cortinas. Portal Novo negócio, 2019. Disponível em: https://novonegocio.com.br/ideias-denegocios/confeccao-de-cortinas/. Acesso em: 29 de julho de 2019.

KLIPPEL CONSULTORES ASSOCIADOS. O Sistema Toyota de Produção, 208. Disponível em www.klippel.com.br. Acesso em: 18 de maio. 2018.

KOTLER, Philip. Administração de marketing: análise, planejamento implementação e controle. 5. ed. São Paulo: Atlas, 1999.

MARTIN, A. Grande Transição. São Paulo, Futura, 1996.

RIBEIRO, M.J. Utilização de Simulação Computacional em Sistemas de Produção sob Demanda de Baixo Tempo de Throughput: Um Estudo de Caso. Dissertação de Mestrado, UFPR, 2004.

SEBRAE. Como montar uma confecção de cortinas? São Paulo: Instituto Monitor, 1990. Disponível em: < http://www.sebrae.com.br/sites/PortalSebrae/ideias/Comomontar-umaconfec\% C3\%A7\%C3\%A3o-de-cortinas.

SHINGO, Singeo. Sistemas de Produção com Estoque Zero: O Sistema Shingo para Melhorias Contínuas. Porto Alegre: Bookman, 1997.

Enviado: Outubro, 2018.

RC: 35968

Disponível em: https://www.nucleodoconhecimento.com.br/administracao/controle-da-producao 
Aprovado: Agosto, 2019. 